\title{
Pancreaticobiliary Fistula Evident after ESWL Treatment of Pancreatolithiasis
}

\author{
Norikazu Arakura ${ }^{1}$, Yayoi Ozaki ${ }^{1}$, Masafumi Maruyama ${ }^{1}$, Yoshimi Chou ${ }^{1}$, Ryou Kodama ${ }^{1}$, \\ Mari Takayama ${ }^{1}$, Hideaki Hamano ${ }^{1}$, Eiji Tanaka ${ }^{1}$ and Shigeyuki Kawa ${ }^{2}$
}

\begin{abstract}
Here we report a patient with a pancreaticobiliary fistula that was possibly associated with pancreatolithiasis. He was admitted due to mild pancreatitis. Pancreatolithiasis was revealed in the parenchyma of the head region and in the main pancreatic duct of the pancreas body with distal dilatation. Extracorporeal shock wave lithotripsy (ESWL) effectively eliminated the pancreatic stones; however, an apparent internal fistula from the middle portion of the common bile duct (CBD) to the main pancreatic duct was revealed where the parenchymal stones had been located. The patient was considered to be in the same condition as pancreato-biliary malunion without CBD dilatation, and was treated with laparoscopic cholecystectomy.
\end{abstract}

Key words: pancreaticobiliary fistula, pancreatolithiasis, extracorporeal shock wave lithotripsy

(Inter Med 48: 545-549, 2009)

(DOI: 10.2169/internalmedicine.48.1788)

\section{Introduction}

Pancreaticobiliary fistula is a rare condition generally associated with pancreatic pseudocysts (1-18), acute necrotizing pancreatitis $(19,20)$, pancreatic abscesses $(21,22)$, and intraductal papillary-mucinous pancreatic neoplasm (IPMN) (23-25). This pathological condition generally presents symptoms such as hemobilia or obstructive jaundice soon after fistulous formation, or is found pathologically after operation on pancreatic pseudocysts caused by acute pancreatitis (13). Here, we report a patient with pancreaticobiliary fistula with an acute attack of chronic pancreatitis due to the compression of the main pancreatic duct (MPD) by pancreatolithiasis, which in turn caused stasis of pancreatic juice and formation of pancreatolithiasis in the distal MPD. In this case, pancreatobiliary fistula became apparent after elimination of stones by extracorporeal shock wave lithotripsy (ESWL), indicating that the pancreatic stone in the fistula had blocked communication between the fistula and MPD. Because this pancreaticobiliary fistula was considered to be the same condition as pancreato-biliary malunion without dilatation of the common bile duct (CBD), we per- formed only laparoscopic cholecystectomy to prevent the occurrence of malignancy.

\section{Case Report}

A 66-year-old man who was an alcoholic with no history of acute pancreatitis, pancreatic cysts or severe abdominal pain complained of epigastralgia and nausea and visited his family physician in March 2006. Blood tests showed elevation of serum amylase, and computed tomography (CT) revealed mild acute pancreatitis with pancreatolithiasis and dilatation of the distal MPD (Fig. 1). He was treated with drip infusion, nafamostat mesylate and antibiotics during 14 days of hospitalization, and improved. The patient was subsequently referred to our hospital for ESWL treatment of pancreatolithiasis. Blood tests showed elevation of fast plasma glucose and CRP (Table 1). CT, magnetic resonance cholangio-pancreatography (MRCP) and endoscopic retrograde cholangio-pancreatography (ERCP) showed compression and narrowing of MPD at the head region due to pancreatolithiasis in the parenchyma (Figs. 2, 3a, 4a, 4b), which in turn resulted in dilatation and stone formation in the distal MPD. We performed ESWL treatment (LITHOSTAR SC

${ }^{1}$ Department of Gastroenterology, Shinshu University School of Medicine, Matsumoto and ${ }^{2}$ Department of Health, Safety and Environmental Management, Shinshu University, Matsumoto

Received for publication October 16, 2008; Accepted for publication December 9, 2008

Correspondence to Dr. Norikazu Arakura, arakuran@shinshu-u.ac.jp 
6002XL, Siemens, Erlangen, Germany) for pancreatolithiasis, as the pancreatitis attack was thought to be induced by parenchymal stones that compressed and narrowed MPD, resulting in stasis of pancreatic juice. After complete elimination of stones by ESWL, MRCP and ERCP showed apparent pancreaticobiliary fistula between the branched pancreatic duct and middle portion of CBD in a manner of $\mathrm{Y}$ with separated orifices at the CBD end (Figs. 3b, 5a, 5b), and collected bile juice showed elevation of amylase $(65,250 \mathrm{U} /$ L). As this pancreaticobiliary fistula was considered to be the same condition as pancreato-biliary malunion without dilatation of CBD, and as the MPD stenosis and the fistula had not changed during 4 months of follow-up periods, we performed only laparoscopic cholecystectomy to prevent the occurrence of biliary malignancy. Pathological findings of gall bladder showed mild diffuse chronic inflammatory change, but not hyperplasia of the epithelium, which is frequently observed in cases of pancreato-biliary malunion.

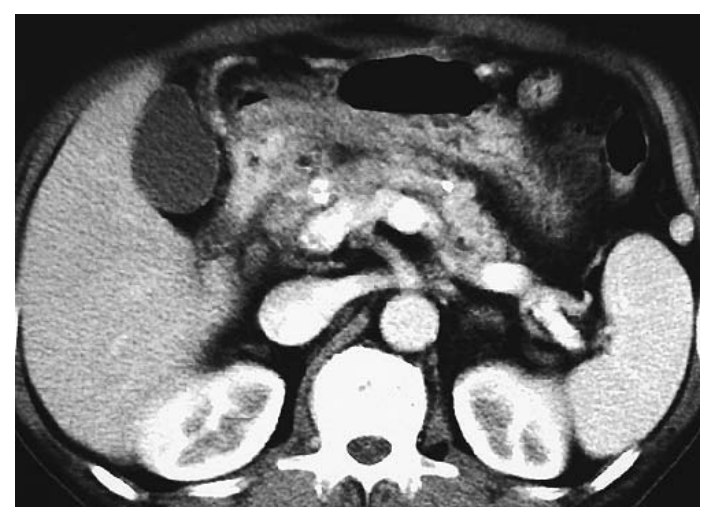

Figure 1. Abdominal CT scan showing mild acute pancreatitis. Slight effusion induced by pancreatitis was observed around the head of pancreas.

Discussion

Pancreaticobiliary fistulae are rarely seen complications of chronic pancreatitis, and are usually formed secondary to the formation of pancreatic pseudocysts (1-18), acute necrotizing pancreatitis $(19,20)$, pancreatic abscesses $(21,22)$, and intraductal papillary-mucinous pancreatic neoplasm (IPMN) (23-25), except for iatrogenic causes (26). This rare condition is also caused by pancreatic tuberculosis (27). Pancreaticobiliary fistulization is generally thought to be formed after compression of the expanding cyst to the bile duct wall and resultant inflammatory reaction in cases of pancreatic pseudocyst. Even in cases of IPMN, tumor invasion to the bile duct wall occurred in only $50 \%$ of the reported cases, and the other $50 \%$ of the cases were considered to be derived from cystic compression to the bile duct and inflammation as shown in pancreatic psuedocysts (23).

The pathogenesis of the present panceaticobiliary fistuli-

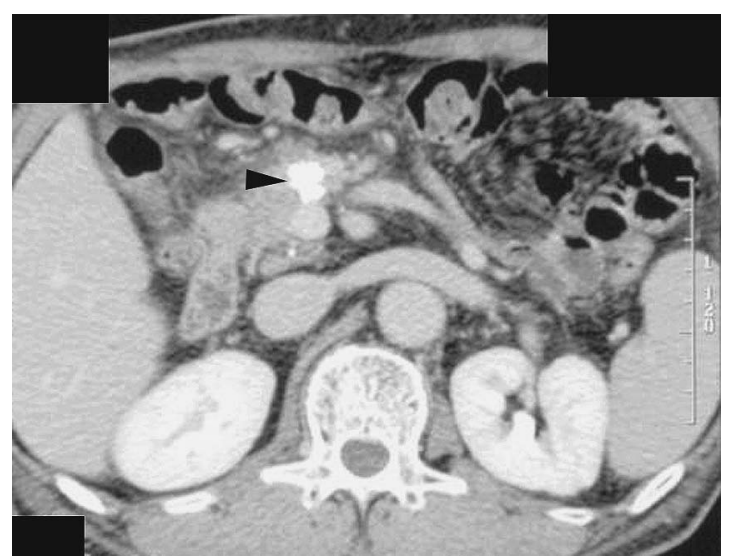

Figure 2. Abdominal CT scan on admission. The arrowhead indicates pancreatolithiasis in the pancreatic head.

Table 1. Patient Laboratory Data

\begin{tabular}{llll}
\hline Hematology & & AMY & $63 \mathrm{mg} / \mathrm{dL}$ \\
WBC & $4360 / \mathrm{mm}^{3}$ & BUN & $11 \mathrm{mg} / \mathrm{dL}$ \\
RBC & $439 \times 10^{4} / \mathrm{mm}^{3}$ & $\mathrm{Cr}$ & $0.79 \mathrm{mg} / \mathrm{dL}$ \\
$\mathrm{Hb}$ & $13.9 \mathrm{~g} / \mathrm{dL}$ & $\mathrm{Na}$ & $142 \mathrm{mEq} / \mathrm{L}$ \\
$\mathrm{Ht}$ & $41.3 \%$ & $\mathrm{~K}$ & $3.3 \mathrm{mEq} / \mathrm{L}$ \\
Plt & $19.5 \times 10^{4} / \mathrm{mm}^{3}$ & $\mathrm{Cl}$ & $104 \mathrm{mg} / \mathrm{dL}$ \\
& & $\mathrm{Ca}$ & $8.6 \mathrm{mg} / \mathrm{dL}$ \\
Blood Chemistry & & Fast plasma glucose & $126 \mathrm{mg} / \mathrm{dL}$ \\
TP & $7.2 \mathrm{~g} / \mathrm{dL}$ & & \\
Alb & $4.1 \mathrm{~g} / \mathrm{dL}$ & Serological examination \\
T. Bil & $0.92 \mathrm{mg} / \mathrm{dL}$ & $\mathrm{CRP}$ & $0.60 \mathrm{mg} / \mathrm{dL}$ \\
D. Bil & $0.50 \mathrm{mg} / \mathrm{dL}$ & HbAlc & $5.6 \%$ \\
AST & $14 \mathrm{IU} / \mathrm{L}$ & $\mathrm{CEA}$ & $2.3 \mathrm{ng} / \mathrm{mL}$ \\
ALT & $7 \mathrm{IU} / \mathrm{L}$ & $\mathrm{CA} 19-9$ & $19.7 \mathrm{U} / \mathrm{mL}$ \\
ALP & $321 \mathrm{IU} / \mathrm{L}$ & & \\
$\gamma$-GTP & $20 \mathrm{U} / \mathrm{L}$ & & \\
\hline
\end{tabular}




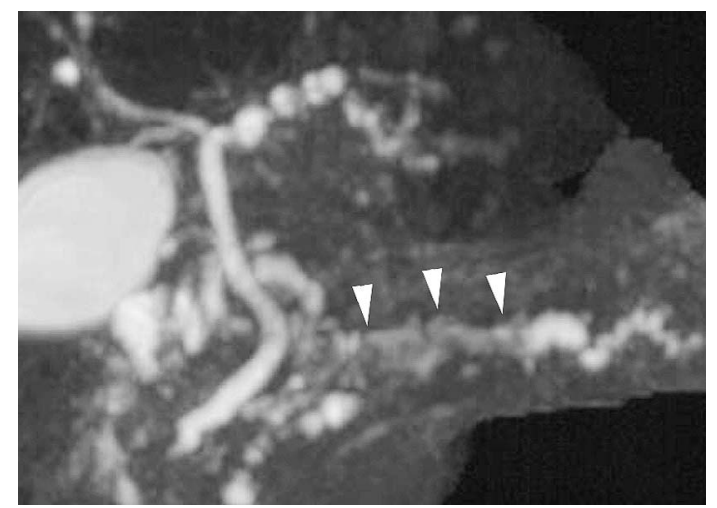

Figure 3a. MRCP on admission. The arrowheads indicate pancreatolithiasis with a low intensity area in the main pancreatic duct.

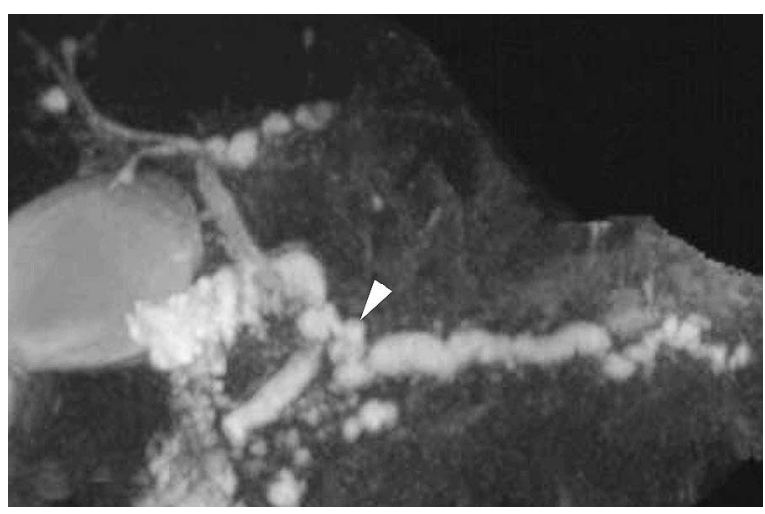

Figure 3b. MRCP after extracorponeal shock wave lithotripsy (ESWL). A pancreaticobiliary fistula (arrowhead) was found between the dilated branch where pancreatolithiasis was found before ESWL and the middle portion of the bile duct.

zation is possibly due to either of the following mechanisms: 1) a pancreatic pseudocyst, which previously formed after alcoholic pancreatitis but was now absent and communicated to the CBD, or 2) a branched intraductal stone had induced the stasis of pancreatic juice, which in turn injured the bile duct wall directly, resulting in pancreaticobiliary fistulization. Regarding the first mechanism, the patient had previously shown no apparent symptoms due to pseudocyst formation. As it is implausible that the panceaticobiliary fistula had formed without apparent symptoms, we believe the first mechanism can be ruled out. On the other hand, it is possible that the stone in the branched duct induced fistula formation, because the dilated fistula divided in a Y manner and communicated with the bile duct separately with the same shape of branched pancreatic ducts. However, it is difficult to determine which mechanism functioned in the pathogenesis, and whether the pancreatic stone caused the fistula or was a result of fistula.

There have been few reports of pancreaticobiliary fistula with pancreatolithiasis. The reason for this small association between pancreatolithiasis and pancreaticobiliary fistula is early diagnosis or prompt treatment of fistulization seen in

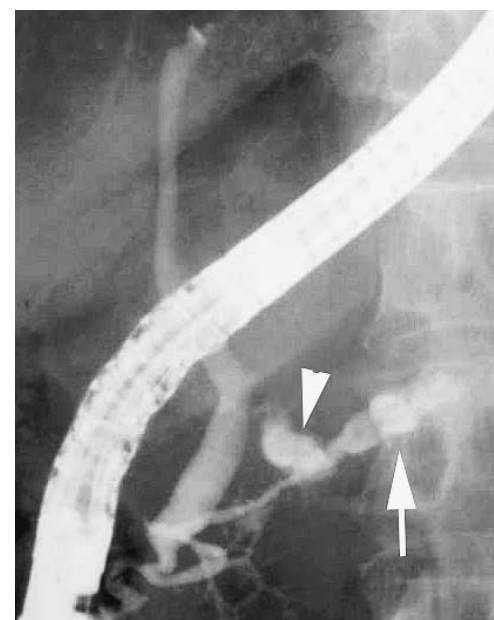

Figure 4a. ERCP on admission showed narrowing of the main pancreatic duct of the pancreatic head with distal dilation. Pancreatolithiasis was found near the narrowing of the main pancreatic duct (arrowhead) and in the main pancreatic duct of the pancreatic body (arrow).

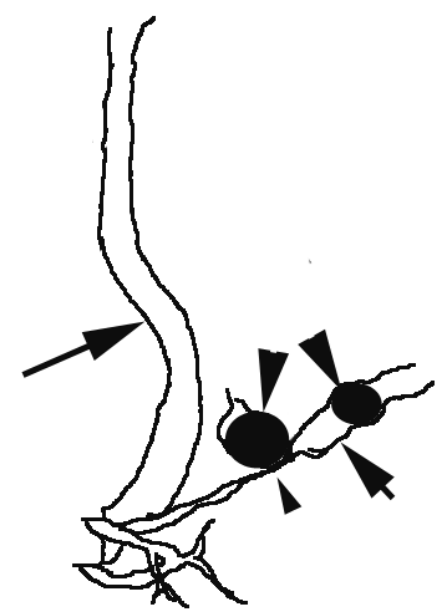

Figure 4b. Schema of Figure 4a. Common bile duct (long arrow), main pancreatic duct (short arrow), pancreatic stone (arrowhead), narrowing of the main pancreatic duct (small arrowhead)

common pathological conditions of expanding pancreatic pseudocysts derived from acute pancreatitis or internal hemorrhage (13), and obstructive jaundice found in IPMN (24). If a stone in the branched duct caused the stasis of pancreatic juice and made a small retention cyst without symptoms, which in turn injured the bile duct wall and resulted in fistula formation, the pancreaticobiliary fistula was not detectable because the stone obstructed the fistula as in this present case.

Therapy for pancreaticobiliary fistula in IPMN has primarily been surgical resection of tumor and fistula (24). Transarterial embolism, endoscopic pseudocyst drainage and surgical resection have been performed in cases of pseudocysts, as hemobilia derived from intracystic bleeding or acute growth required prompt therapy (17). There has been 


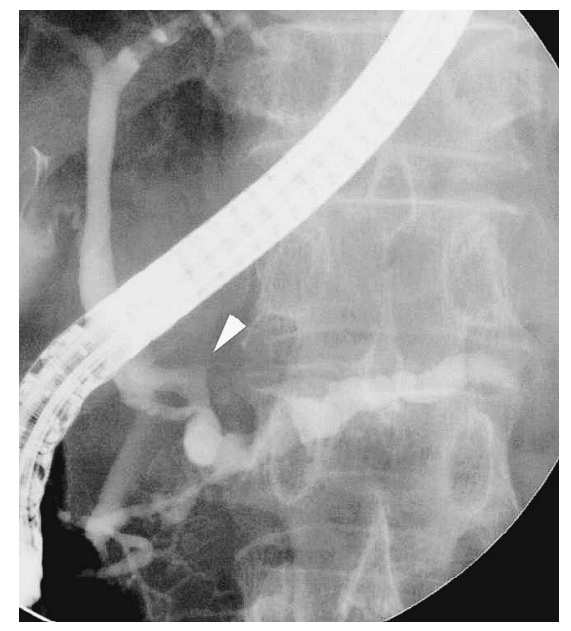

Figure 5a. ERCP after extracorponeal shock wave lithotripsy (ESWL) showed pancreaticobiliary fistula (arrowhead) between the dilated branch where the stone was found before ESWL and the middle portion of the bile duct in a manner of $\mathrm{Y}$ with separated orifices at the CBD end.

no agreement concerning the direct treatment for pancreaticobiliary fistula, as the preoperative diagnosis for this condition is very difficult to ascertain. Several patients with this disease were conservatively treated with a pancreatic stent $(16,21,22)$. We were unable to perform pancreatic stent therapy for this patient, as we concluded that the pancreaticobiliary fistula would not close with this procedure due to long stricture of the main pancreatic duct and diffusely apparent pancreaticobiliary fistula. Because the condition had not changed during 4 months of follow-up periods, we selected only cholecystectomy according to the standard treatment of pancreato-biliary malunion without dilatation of the

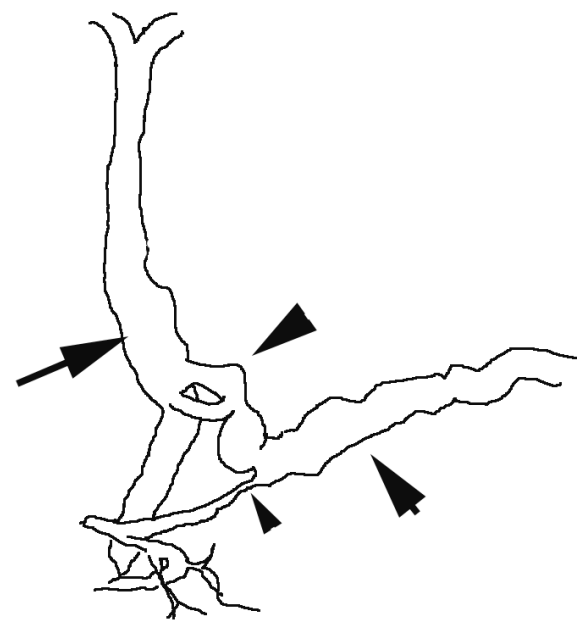

Figure 5b. Schema of Figure 5a. Common bile duct (long arrow), main pancreatic duct (short arrow), pancreaticobiliary fistula (arrowhead), narrowing of the main pancreatic duct (small arrowhead)

CBD in order to prevent the occurrence of gallbladder cancer. The lack of dilatation of CBD and the patient's old age did not favor the choice of pancreatoduodenectomy. Pathological findings of gall bladder showed mild diffuse chronic inflammatory change, though hyperplasia of the epithelium is frequently observed in cases of pancreato-biliary malunion. The primary reason for this absence of hyperplasia was thought to be related to the short duration after fistula formation or obstruction of the fistula by pancreatic stone.

In conclusion, we report a rare case of pancreaticobiliary fistula that was evident after ESWL treatment of pancreatolithiasis, and speculate that the stone in the branched duct possibly caused the fistula formation.

\section{References}

1. Glass R, Newstedt J. Hemobilia: an unusual complication of chronic pancreatitis. Missouri Med 61: 853-854, 1964.

2. Dalton W, Lee H, Williams G, Hume DM. Pancreatic pseudocyst causing hemobilia and massive gastrointestinal hemorrhage. Am J Surg 120: 106-107, 1970.

3. Sankaran S, Walt A. The natural and unnatural history of pancreatic pseudocysts. Br J Surg 62: 37-44, 1975.

4. Grace R, Jordan P. Unresolved problems of pancreatic pseudocysts. Ann Surg 184: 16-21, 1976.

5. Ro JO, Yoon BH. Pancreatic pseudocyst as a cause of gastrointestinal bleeding and hemobilia. A case report. Am J Gastroenterol 66: 287-291, 1976.

6. Ellenbogen KA, Cameron JL, Cocco AE, Gayler BW, Hutcheon DF. Fistulous communication of a pseudocyst with the common bile duct: demonstration by endoscopic retrograde cholangiopancreatography. Johns Hopkins Med J 149: 110-111, 1981.

7. Gadacz TR, Lillemoe K, Zinner M, Merrill W. Common bile duct complications of pancreatitis evaluation and treatment. Surgery 93: 235-242, 1983.

8. DeVanna T, Dunne MG, Haney PJ. Fistulous communication of pseudocyst to the common bile duct: a complication of pancreatitis. Pediatr Radiol 13: 344-345, 1983.

9. Skellenger M, Pattersson D, Foley N, Jordan PH. Cholestasis due to compression of the common bile duct by pancreatic pseudocyst. Am J Surg 145: 343-348, 1983.

10. Bresler L, Vidrequin A, Poussot D, et al. Fistulous communication of a pancreatic pseudocyst with the common bile duct: demonstration by operative cholangiogram [letter]. Am J Gastroenterol 84: 835-836, 1989.

11. Verma GR, Kochhar R, Nagi B. Duodeno-pancreatico-choledochal rupture of pseudocyst. [Letter]. Gastrointest Endosc 37: 588-589, 1991.

12. Dumas O, Jouffre C, Desportes R, Etaix J, Barthelemy C, Audigier J. Duodeno-pancreatico-choledochal rupture of pseudocyst. [Letter]. Gastrointest Endosc 37: 588-589, 1991.

13. Hauptmann EM, Wojtowycz M, Reichelderfer M, McDermott JC, Crummy AB. Pancreatic pseudocyst with fistula to the common bile duct: radiological diagnosis and management. Gastrointest Radiol 17: 151-153, 1992.

14. Raimondo M, Ashby AM, York EA, Derfus GA, Farnell MB, Clain JE. Pancreatic pseudocyst with fistula to the common bile duct presenting with gastrointestinal bleeding. Dig Dis Sci 43: 2622-2626, 1998.

15. Carrere C, Heyries L, Barthet M, Bernard J-P, Grimaud J-C, Sahel J. Biliopancreatic fistulas complicating pancreatic pseudocysts: a report of three cases demonstrated by endoscopic retrograde chol- 
angiopancreatography. Endoscopy 33: 91-94, 2001.

16. Apel D, Weickert U, Riemann J. Successful treatment of pancreatobiliary fistula by endoscopic stenting. Scand J Gastroenterol 39: 395-397, 2004.

17. Rasmussen IC, Karlson BM, Löfberg AM. Biliary pancreatic portal fistula as a complication of chronic pancreatitis: a case report with review of the literature. Ups J Med Sci 111: 329-338, 2006.

18. Rickes S, Mönkemuller K, Peitz U, et al. Sonographic diagnosis and endoscopic therapy of a biliopancreatic fistula complicating a pancreatic pseudocyst. Scand J Gastroenterol 41: 989-992, 2006.

19. Miller B, Traverso L, Freeny P. Intrapancreatic communication of bile and pancreatic ducts secondary to pancreatic necrosis. Arch Surg 123: 1000-1003, 1988.

20. Sakorafas G, Sarr M, Farnell M. Pancreaticobiliary fistula: an unusual complication of necrotising pancreatitis. Eur J Surg 167: 151-153, 2001.

21. Saeed ZA, Ramirez FC, Hepps KS. Endoscopic stent placement for internal and external pancreatic fistulas. Gastroenterology 105: 1213-1217, 1993.

22. Schoefl R, Haefner M, Pongratz S, et al. Endoscopic treatment of fistulas and abscesses in pancreatitis: three case reports. Endoscopy 28: 776-779, 1996.

23. Kurihara K, Nagai H, Kasahara K, Kanazawa K, Kanai N. Biliopancreatic fistula associated with intraductal papillarymucinous pancreatic cancer: institutional experience and review of the literature. Hepatogastroenterology 47: 1164-1167, 2000.

24. Okada K, Furuuchi T, Tamada T, et al. Pancreatobiliary fistula associated with an intraductal papillary-mucinous pancreatic neoplasm manifesting as obstructive jaundice: report of a case. Surg Today 38: 371-376, 2008.

25. Sano S, Nishimori I, Okamoto N, et al. Biliopancreatic fistula caused by an intraductal papillary-mucinous tumor of the pancreas confirmed by biochemical analysis of mucin. Int $\mathrm{J}$ Gastrointest Cancer 34: 101-106, 2003.

26. Herrington JL Jr, Vasudeo P. Iatrogenic choledochal stricture with choledochopancreatic fistula and pseudocyst. Arch Surg 112: 213216, 1977

27. Nakai Y, Tsujino T, Kawabe T, et al. Pancreatic tuberculosis with a pancreaticobiliary fistula. Dig Dis Sci 52: 1225-1228, 2007.

(C) 2009 The Japanese Society of Internal Medicine http://www.naika.or.jp/imindex.html 